\title{
Automatic Tooth Color Tester Device
}

\author{
Ipin Prasojo ${ }^{1 *}$, Nishith Shahu ${ }^{2}$, Lastuti Abubakar ${ }^{2}$, Irfan Ahmad $^{3}$, Nia Maharani \\ Raharja ${ }^{4}$ \\ ${ }^{1}$ Department of Electrical Engineering, ITS PKU Muhammadiyah Surakarta, Solo, Surakarta \\ ${ }^{2}$ polytechnic college to Gujarat Technological University, India \\ ${ }^{3}$ Khurasan university, Nangarhat, Afghanistan \\ ${ }^{4}$ Department of Electrical Engineering, Universitas Islam Negeri Sunan Kalijaga, Yogyakarta, Indonesia \\ *rmprasojo@gmail.com
}

\begin{abstract}
Teeth have a very meaningful function for humans which is to nelp hew, cut food. Therefore the teeth must be treated properly. Although treatment ha been one but there are still changes in tooth color. This device can reduce human error 1 medical officers who conduct examinations. Besides these things, this de ice is also very useful for determining the colors of teeth in accordance with existing par eterc $\mathrm{In}$ this module the average percentage of errors in the color of white te th is $+2,2 \%$, the color of yellow teeth is $+2.53 \%$, while the color of brown teeth $-2.34 \%$, and the Ua value of the measurement results is 0.01 while the U95 value is 0.04 . From the results of voltage measurements on the colors of yellow and brown there is the same voltage, this is due to differences in the thin color of the teeth, ne mea surement position of the reading and selection of sensors and the light source used.
\end{abstract}

Keywords:Tooth color, LDR sensor, LEL mirocontroller.

\section{Introduction}

In line with the increasingl, rapid advances in technology that encourage people to think about doing activities and activities easily and lightly, so the old ways and need a long time are increasingly abar don $\mathrm{d}$. In the field of medicine, the development of this technology will facilitate the operation of $\mathrm{m}$ dical device, one of which is a teeth instrument.

As it is kn that tweth are an important part in the process of digestion. With genetic influences a a ey angl influences such as diet and differences in tooth sensitivity, can affect tooth color. Ac ording to the author's observations of the examination of tooth discoloration is currently still done manually by means of matching with the teeth color measurement card.

\section{Method}

The research design used in the preparation of this Final Project is a research design that is Pre-Experimental. This type of research used in the preparation of this Final Project is a type of research "After Only Design" which is only to see the results of teeth color measurement automatically without seeing before. But there is already a control group that is measuring the color of teeth manually. The weakness of this study is that it does not know the initial situation, so the results obtained are difficult to conclude. 